\title{
Getting a Sharper View of the Humanitarian Marketplace: Introducing Conduit Engagement Theory
}

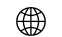 \\ Joseph G. Bock and Ziaul Haque
}

\begin{abstract}
There are differing views on the strengths and weaknesses of faith-based organizations relative to secular international nongovernmental organizations. This article argues that the theory of comparative advantage and the theory of organizational alignment are inadequate in helping to assess these strengths and weaknesses. The article offers a different perspective, called conduit engagement theory. It holds that humanitarian organizations naturally have specific relationships, organizational linkages, affiliations, or shared philosophies (referred to in the article as conduits) that enable certain programmatic interventions. Maximum effectiveness within the humanitarian marketplace is a function of the robustness of engagement of conduits with high-priority initiatives that have adequate funding over the necessary length of time. A new kind of tool for strategic planning within specific countries and for auditing at an organizational level are proposed. KEYWORDS: faith-based organizations, comparative advantage, public funding.
\end{abstract}

WHAT UNIQUE CAPABILITIES DO FAITH-BASED ORGANIZATIONS (FBOS) HAVE RELATIVE to their secular counterparts? Is there more to be considered when deciding on a humanitarian course of action than mission fit and resource availability? Is it always a good idea to pursue the acquisition of public grants?

The subject of this article was conceived during a conversation I ("I" in this article refers to the first author, Joseph G. Bock) had with a US Agency for International Development (USAID) official at a workshop at the United States Institute of Peace in 2015. The USAID official had worked in Haiti after its devastating earthquake in 2010. I had worked there also, as an interim country director for a secular international nongovernmental organization (INGO). I commented on how it was unfortunate that FBOs did not focus more of their attention in Haiti on program areas that are difficult to address, relatively speaking, for secular INGOs, governmental aid agencies and multilateral organizations (MOs). Given that Catholicism is the predominant religion in Haiti (albeit sometimes combined with vodou), I expressed consternation that Catholic FBOs were "chasing public funds" (from governments and from MOs like the United Nations), using their private resources to match those funds, while failing to address challenges that they were uniquely positioned to address. I pointed out, as an example, how Catholic 
FBOs from outside Haiti could have developed a partnership with the Haitian Catholic Church designed to address a major obstacle to Haiti's developmentnamely, rampant corruption. Instead, they were focusing on getting grants for temporary shelters and public health projects just like secular INGOs.

The USAID official responded affirmatively and enthusiastically. She then urged me to write an article articulating my main points. This is that article, which I have written with one of my PhD students.

Some of the observations appearing in this article are a reflection of my twelve years of humanitarian experience. I worked eight years for Catholic Relief Services - two in its Baltimore, Maryland, headquarters as director of development education; three in Islamabad, Pakistan, as country representative; and another three in Jerusalem/West Bank/Gaza as country representative. In addition, I worked another four years for the American Refugee Committee in three different executive roles - first as deputy executive officer, then as interim executive director, and later as vice president.

In this article, we present a lens through which the unique role of FBOs relative to secular INGOs can be analyzed. We call it conduit engagement theory. It builds on, but differs from, David Ricardo's classic theory of comparative advantage. It also borrows from alignment theory of management science. We offer examples of how conflict engagement theory provides insight to achieve optimal humanitarian results. We then test two hypotheses derived from our theory. We address what this theory implies for effectiveness within the humanitarian marketplace. ${ }^{1}$ Finally, we conclude with a description of how to operationalize this theory as part of a strategic planning process at a country level and as an added dimension of an audit at an organizational level.

This article does not relate to secularization theory in that it is not about declining participation in organized religion. ${ }^{2}$ Neither does it focus on the reduced influence of religious authority, as explored by neosecularization theory. ${ }^{3}$ Instead, our focus is on the unique value-added capacities of FBOs, on their conduits and the impact of public funding on engaging those conduits.

\section{FBOs as Compared to Secular INGOs}

When we refer to faith-based organizations, we mean organizations with a religious identity, as distinct from secular international nongovernmental organizations. We choose not to distinguish FBOs from missionaries inasmuch as there are varying degrees of explicitness of religiosity and aggressiveness of evangelism within both categories. On one end of the continuum are organizations that have an understated religious identity that do not engage in evangelism whatsoever. In the middle are organizations that have visible signs of their faith and are engaged in "lifestyle evangelism," as in living out religious strictures, but only vocalizing religiosity when someone brings it up such as in asking why they do the work they do. On the other end of the continuum are organizations 
that encourage nonbelievers to participate in sacred rituals. These FBOs engage in proselytism, deliberately and aggressively seeking to convert people to the organization's religion. ${ }^{4}$

There is a widespread criticism among secular institutions and many religious institutions that proselytizing by providing humanitarian assistance is unethical, coercive, and inappropriate. Lifestyle evangelism, on the other hand, is not seen typically as having that coercive quality.

Secular INGOs, in contrast, do not have a religious identity as organizations, though individual workers may or may not be religious. ${ }^{5}$ Some employees of secular INGOs might, as individuals or groups, have relationships with faith communities associated with their religious identities if they have any. So, for instance, a group of employees of a secular INGO might worship at the same mosque, developing relationships within the local Muslim community. ${ }^{6}$

Because the degree of religiosity of FBOs varies widely, and due to the presence of religious individuals or groups within secular INGOs, comparing the two can be flawed. We concur with the view offered by Emma Tomalin that "a more context-sensitive and case-by-case approach is recommended ... studies that highlight situations or activities in which FBOs appear to be more effective and have greater impact, as well as analyses that indicate where they have created problems, can assist development donors and practitioners to better understand the potential contribution of FBOs to development in different contexts." 7

In this article, we offer a way to identify potential contributions of FBOs relative to secular INGOs. We argue that distilling which organization should focus on what initiatives requires an assessment of the overall humanitarian marketplace, and a check on pursuing donor-driven projects.

\section{Comparative Advantage and Alignment Theories}

There is a well-developed literature on the strengths and weaknesses of FBOs relative to secular INGOs. ${ }^{8}$ Alyson Lipsky, for instance, analyzes their differences using Ricardo's classic theory of comparative advantage..$^{9}$ Ricardo developed his theory to illustrate how two countries can benefit by specializing and trading, even if one of the countries is more efficient at producing goods of every category. ${ }^{10}$

The theory of comparative advantage is not particularly helpful when assessing the strengths and weaknesses of FBOs compared to INGOs. The first reason is that the religiosity and evangelism of FBOs varies and that religious people work for secular INGOs. As Tomalin points out, "There is little evidence that many of the supposedly distinct characteristics of FBOs are exclusive to or more prevalent in them than other sorts of organizations." 11 Yet there are differences to acknowledge. Lipsky, for instance, offers evidence of superior performance in health services in sub-Saharan Africa being provided by FBOs as compared to 
secular INGOs. These differences are ascribed to FBOs due to their "moral and ethical standing" more so than their religiosity. ${ }^{12}$

A second reason comparative advantage does not apply particularly well to assessing strengths and weaknesses of FBOs relative to secular INGOs relates to the nature of humanitarianism, or what has been called the humanitarian marketplace. The humanitarian marketplace consists of the aggregate human needs in a given area and the interplay of the various service providers focused on satisfying those needs. Needs are not all satisfied by tangible inputs, whereas the benefits of trade are measured in goods and services. Maximum efficiency within the humanitarian marketplace relates to the dogged pursuit of impactful initiatives that may or may not be measured in goods and services, nor in monetary terms. With comparative advantage, goods and services are traded. In the humanitarian marketplace, goods and services are produced by a given society or by outsiders, or both. They are not traded. ${ }^{13}$

Conduit engagement theory holds that some FBOs and secular INGOs have unique capacities to use in the overall humanitarian aid effort, and to not focus on them is a missed opportunity even when the FBO or secular INGO receives less grant funding. In the case of comparative advantage, firms seek to maximize their profits. Using this same view in the humanitarian marketplace, FBOs and secular INGOs seek to maximize their public and private resources (though their "profits" are grants and donations). They are often asked to match public grants with private resources. The public grants are focused on areas a donor wants addressed, and the funds from private sources for the match are typically focused on those same objectives.

With conduit engagement theory, in contrast, the focus is not on profit (as in acquiring grants and donations), but on identifying unique capacities that are discernable as avenues to addressing difficult challenges. To engage a unique conduit, an FBO or secular INGO sometimes has to allocate its private resources to a programming area either not of interest to public donors or out of the scope of public donors due to the explicit religious nature of the initiative being undertaken. ${ }^{14}$

To illustrate, going back to the example of Haiti mentioned above, let us assume CARE, Save the Children (SAVE), and Catholic Relief Services (CRS) are operating there. CARE is efficient at building temporary shelters while SAVE excels at building latrines. CRS is not as good at building shelters as CARE, but is equal in its ability to build latrines as SAVE. If we were to confine ourselves to comparative advantage theory, the optimum allocation of resources by USAID would be to support CARE in building temporary shelters and SAVE or CRS in building latrines. Assume private donors have been equally generous to all three INGOs and each has enough private support to cover USAID's matching requirements.

Let us assume USAID has $\$ 25$ million to spend on temporary shelters, but expects to get at least $\$ 500,000$ in matching private funds. For a total of $\$ 25.5$ million, CARE proposes that it will build 100,000 temporary shelters, SAVE pro- 
poses 95,000 , and CRS proposes 90,000. For latrines, USAID offers $\$ 10$ million in grant support, expecting a $\$ 300,000$ private match. As shown in Table 1 , for that amount, CARE could build 60,000, SAVE 80,000, and CRS 80,000 latrines. USAID's optimum grant allocation would be to fund CARE for temporary shelters and SAVE or CRS for latrines.

\section{Table 1 Program Output (Number of Units)}

\begin{tabular}{cccc}
\hline Grant and Match & CARE & SAVE & CRS \\
\hline Temporary shelters & 100,000 & 95,000 & 90,000 \\
25 million public & & & \\
500,000 private & & & \\
Latrines & 60,000 & 80,000 & 80,000 \\
10 million public & & & \\
300,000 private & & & \\
\hline
\end{tabular}

Source: Table constructed by the authors

Note: SAVE, Save the Children; CRS, Catholic Relief Services.

If we introduce another programming area that would involve the engagement of an organizational conduit, we get a different result. In this case, the conduit is the link between the Catholic Church of the United States with Catholic institutions and leaders within Haiti. Table 2 shows that CRS decides not to submit a proposal to USAID. CARE still gets an award to build temporary shelters, SAVE gets the award for latrines, and CRS puts the $\$ 300,000$ it was going to spend on latrines into an anticorruption initiative, working with the local church. In this case, anticorruption is addressed as a moral issue underpinned with theology, possibly involving a sacred ritual such as confession. Assuming a relatively pronounced division between what is secular and religious, this is an initiative that USAID would not likely support.

\section{Table 2 Funding Reflecting Conduit Engagement (US dollars)}

\begin{tabular}{llll}
\hline Grant and Match & CARE & SAVE & CRS \\
\hline $\begin{array}{l}\text { Temporary shelters } \\
25 \text { million public }\end{array}$ & $\$ 25,500,000$ & & \\
500,000 private & & \\
Latrines & $\$ 10,300,000$ & \\
$\quad 10$ million public & & \\
$\quad 300,000$ private & & \\
Anticorruption working through & & \\
$\begin{array}{l}\text { Catholic institutions and leader- } \\
\text { ship }\end{array}$ & & \\
\hline
\end{tabular}

Source: Table constructed by the authors

Note: SAVE, Save the Children; CRS, Catholic Relief Services. 
The optimal formulation would be what is depicted in Table 2. CRS earns much less profit. Conduit engagement theory considers not just the financial dimension, but also conduits that are unique for a given FBO or secular INGO. In this example, if both CRS and SAVE build latrines, which they do equally well (i.e., there is no exclusivity), there is a net decrease in the effectiveness of the collective humanitarian enterprise. Conduits are ignored and not engaged. This is humanitarian marketplace failure.

A third reason that comparative advantage theory is not especially helpful is that some humanitarian situations are cooperative rather than competitive. Nina W.T. Hall, for instance, provides evidence of cooperation among organizations related to climate change. ${ }^{15}$

Another theory that could sharpen our analysis is focused on organizational alignment. It comes from management sciences. It posits that an organization's maximum effectiveness is when there is agreement in strategy, structure, and culture. According to alignment theory, agreement among these three variables "facilitates the achievement of organizational goals." 16 Organizational alignment is internal, but relates to the "competitive situation." 17

This theory is helpful for our understanding of the importance of intraorganizational coherency, which is important to interorganizational synchronization. For example, in the 1990s, CRS developed a "justice lens" initiative. ${ }^{18}$ All staff members, regardless of their religious beliefs or lack thereof, were trained in how to use a common, justice-oriented, framework. They were expected to uphold the tenets of Catholic Social Teaching. ${ }^{19}$ Some CRS staff members saw this training initiative as window dressing while others viewed it as a genuine attempt to be true to its religious roots. Another view is that CRS was attempting to engage its conduits more robustly.

Yet as years passed, CRS's bureaucratic inertia, and its reliance on indirect cost recovery to pay staff members skilled in administering large grants, resulted in malalignment. While country representatives were more skilled at using the terminology of the justice lens, they nonetheless knew that their performance was assessed largely on their abilities to secure multiyear, multimillion-dollar grants. In that sense, the financial hunger of the FBO maintained an organizational gravity toward material transfer and large projects while the less expensive, justice-oriented projects did not receive the attention or the financial support that the justice lens initiative portended.

Like comparative advantage, alignment theory falls short for our purposes. This is because alignment theory is largely focused on the effective functioning of an organization, not the wider context which, in our case, is the humanitarian marketplace. Our concern is in which organizations should do what for maximum effectiveness in the overall context of improving the human condition amidst poverty, hunger, disease, illiteracy, oppression, injustice, displacement, violence, and other challenges. As with the justice lens example, it is reasonable to assume that justice-oriented initiatives that would have been helpful were not pursued 
by CRS or any other organization due to a consistent focus on grant acquisition. This is a failure in the humanitarian marketplace.

\section{Conduits of FBOs and Secular INGOs}

Conduit engagement theory aims to sharpen our analyses, guide our programming, and aid in strategic planning and accountability. Conduits consist of relationships, organizational linkages, affiliations, and common philosophies. Relationships are interpersonal, as in when an FBO country director has positive relationships with members of a community-based organization (CBO). They can also be organizational in the sense of "our organization has a good relationship with their organization."

Organizational linkages are conduits when they serve to facilitate communication and joint action. If one of Oxfam's country offices takes a lead in developing an advocacy campaign, for instance, then other organizations throughout the Oxfam network globally are enabled to engage in similar advocacy.

Affiliations serve as conduits in providing for a common language and for natural affinity. For instance, staff members of the American Bar Association are able to readily communicate with lawyers (or advocates) using legal terminology. Attorneys from one country can arguably relate more readily to attorneys in another country.

A common philosophy serves as a conduit in providing a frame of reference and an ethos to which organizations and their staff members can relate. For instance, the health professionals have a common fidelity to the Hippocratic oath.

Conduits are not always unique or exclusive. CRS can have a powerful ability to influence the Catholic Church in Haiti because it has natural linkages with the official Catholic Church hierarchy within that country. Likewise, a non-Catholic but still Christian organization, such as World Vision (WV), which establishes relationships with church officials, has a conduit.

In some countries, religious leaders tend to be frustrated with international FBOs affiliated with that religion, especially when the local faith community comprises a small percentage of the population and the people of that community perceive themselves as being discriminated against (e.g., as do Christians in Pakistan). Church-affiliated FBO country directors sometimes have strained relationships with host country church leaders due to a perception (whether accurate or not) that the official humanitarian arm of the church favors people of other faiths at the expense of people of their own faith. This might not be the case with a non-church-affiliated FBO, especially if it provides more support to the local faith community than the church-affiliated FBO.

Effectiveness relates to whether conduits are positive, neutral, or negative. In this example, the church-affiliated FBO's primary conduit with the host country church hierarchy is a negative conduit, whereas the non-church-affiliated FBO has a positive conduit. Conduits are dynamic, not static. Organizations can 
attempt to turn a negative conduit, for instance, into a positive one, but doing so takes time and effort.

There also are group conduits. As with the example above, a group of employees of a secular INGO who worship at the same place will potentially have a conduit with a faith community as a group, or as individuals. The same is true with staff members of FBOs who have relationships with secular leaders. For example, members of the Community of Sant' Egidio, a Catholic FBO founded in Italy, identified an opportunity to broker peace in Mozambique in 1992. Their relationship with the government of Mozambique was a result, to some extent, of earlier advocacy to relax governmental restrictions on the Catholic Church in that country. The relationship was cultivated, in part, by Enrico Berlinguer, a leader of the Italian Communist Party, who had a natural affinity with the socialist government of Mozambique. ${ }^{20}$ Sant' Egidio's relationship with Berlinguer was a conduit that was engaged to do something that few nondiplomatic organizations do - namely, to broker peace at top levels of government.

Another component of conduit engagement theory relates to the amount of resources required over time. An anticorruption initiative in Haiti probably requires much less money than, say, a project to build shelter for victims of an earthquake. Such an initiative, however, may need a substantial amount of time to be successful - a matter of decades, not years.

Identification of optimal conduit engagement involves five steps:

1. To rank humanitarian initiatives in order of priority. Of course, developing such a list demands adherence to principles of community development, as in asking the community what they perceive as priorities.

2. To identify positive conduits that can be engaged to enable the effective pursuit of those initiatives. Practically speaking, some conduits will likely need to be deliberately cultivated. Others will be established already.

3. To assess the degree of exclusivity of the conduit. This is important inasmuch as there are instances when one FBO or secular INGO has an ability to affect change more profoundly than other organizations. The higher the priority and the greater the exclusivity, the more important it is for the organization to pursue that initiative.

4. To determine if adequate resources are available. The resources are human, material, and financial. There are also intangible resources, such as a commonly held moral code or a shared sacred ritual.

5. To assess the ability to maintain a sustained focus on the intervention for the necessary amount of time. Of course, some initiatives can be completed in a relatively short period, such as in rebuilding after a natural disaster. Others, will take much longer, such as in creating a social movement to change attitudes and practices of men who harass women. $^{21}$ 
FBOs and secular INGOs perennially complain about the short duration of most public grants. They argue that many problems, especially ones that are complex and difficult to address such as corruption, require intense focus over decades. ${ }^{22}$ Assuming FBOs have the private donor base to sustain their efforts over longer periods than the typical duration of public grant funding, what kinds of programs become more possible, and more effective in their developmental impacts, when engaging their conduits?

\section{Hypotheses on Raising Unrestricted Funds and Engaging in Advocacy}

Below, we offer two hypotheses, analyze them, and report our results. We compiled data from a sample of five FBOs and five secular INGOs (categorized based on our reading of their mission statements). We limited our sample to international Christian FBOs, comparing them to secular INGOs. Both groups are exclusively from the United States. This restricted sample is a reflection of the data available to us. ${ }^{23}$ We collected eight to ten years of information on their revenues and expenditures. Our sources were mainly financial statements reported on US Internal Revenue Service (IRS) Form 990 and audit summaries. We also studied their annual reports, as available, and searched websites. The ten organizations, in alphabetical order, are: CARE, CRS, Church World Service (CWS), Médecins Sans Frontières (MSF), Episcopal Relief and Development (ERD), Mennonite Central Committee (MCC), Mercy Corps (MRC), Oxfam America (Oxfam), SAVE, and WV.

Hypothesis 1: Secular INGOs are less able to raise unrestricted funds than FBOs because of organizational conduits FBOs have with their associated faith communities.

To the extent that FBOs have unique conduits that need private unrestricted funds to engage, it would be helpful to know if they tend to be able to raise such funds more readily than secular INGOs. To analyze this, we examined the unrestricted funds of the sample FBOs and secular INGOs. We found that FBOs indeed have greater capacity to raise private unrestricted funds. As Table 3 shows, the top performer among FBOs was MCC, raising an average of \$24.14 for every dollar spent on fund-raising. The average amount of money raised per dollar spent on fund-raising for FBOs was $\$ 13.52$. For secular INGOs, it was $\$ 6.91 .^{24}$ This hypothesis, therefore, is supported by the evidence. ${ }^{25}$

Hypothesis 2: The greater the public support, the less likely an organization will advocate for structural change.

With this hypothesis, we sought to illuminate the role of public as compared to private funding of FBOs. To some authors, public funding has distracted some FBOs from pursuing important challenges that they are uniquely able to address. Nathan Grills argues, for instance, that public funding often contracts the scope 
Table 3 Amount Raised Per Dollar by FBOs Compared to Secular INGOs, 2008-2015

\begin{tabular}{lrrrrrrrrrr}
\hline \multicolumn{3}{c}{ FBOs } & \multicolumn{8}{c}{ Secular INGOs } \\
Year & \multicolumn{1}{c}{ CRS } & CWS & ERD & MCC & WV & CARE & MRC & MSF & Oxfam & SAVE \\
\hline 2008 & 8.65 & 1.06 & 7.28 & 64.77 & 13.34 & 11.39 & 3.46 & 7.45 & 0.27 & 9.89 \\
2009 & 8.66 & 0.89 & 9.47 & 57.49 & 66.83 & 9.23 & 2.85 & 7.09 & 5.69 & 7.39 \\
2010 & 14.44 & 0.84 & 16.18 & 6.61 & 65.73 & 10.96 & 8.26 & 13.31 & 7.59 & 9.29 \\
2011 & 10.89 & 2.62 & 10.42 & 7.01 & 5.47 & 11.88 & 6.16 & 4.07 & 6.99 & 8.36 \\
2012 & 9.02 & 1.18 & 10.43 & 6.48 & 5.30 & 10.74 & 5.61 & 3.53 & 0.30 & 7.37 \\
2013 & 8.50 & 0.69 & 11.86 & 16.80 & 5.23 & 10.06 & 5.06 & 4.06 & 0.57 & 7.71 \\
2014 & 11.83 & 0.94 & 9.90 & 15.75 & 5.59 & 11.81 & 5.78 & 5.19 & 5.15 & 6.73 \\
2015 & 11.60 & 0.70 & 6.32 & 18.24 & 5.95 & 11.87 & 6.76 & 4.25 & 7.03 & 5.17 \\
Average & 10.45 & 1.12 & 10.23 & 24.14 & 21.68 & 10.99 & 5.49 & 6.12 & 4.20 & 7.74 \\
\hline
\end{tabular}

Source: Numbers generated from financials

Note: FBOs, faith-based organizations; INGOs, international nongovernmental organizations; CRS, Catholic Relief Services; CWS, Church World Service; ERD, Episcopal Relief and Development; MCC, Mennonite Central Committee; WV, World Vision; MRC, Mercy Corps; MSF, Médecins Sans Frontières; Oxfam, Oxfam America; SAVE, Save the Children.

of FBO programs, as such engagements clash with the Enlightenment ideology of many secular funding platforms ${ }^{26}$ Michael Edwards and David Hulme point out that public funding has the potential to undermine FBOs' distinct capacity as faith communities, increasing their monetary dependency on grants and decreasing their downward accountability to religious grassroots supporters. ${ }^{27}$ Numerous other observers contend that public funding can drive up administrative costs due to increased reporting, monitoring, and evaluation required by the donors of these funds. ${ }^{28}$

On the other hand, public funding clearly increases resources of FBOs, helping them expand their services to a variety of audiences. ${ }^{29}$ Moreover, it is arguable that public funding enhances social acceptability and legitimacy of FBOs among their private donors since receiving institutional financial support can be viewed as indicative of well-developed operational and service delivery capacity.

It is important to acknowledge that there are internal debates within FBOs about the impacts of public funding. There are efforts to balance the desire to maximize public funding (along with private funding) in an effort to help more people while, at the same time, imbuing programming with the tenets of a particular faith tradition. To the extent that public funding has a material impact on the programmatic choices of FBOs, it is important to define and measure what that impact is.

One area of concern is how receiving public funding impacts the extent to which an FBO or secular INGO focuses on structural change (the reasons behind the poverty, violence, or other challenge) as compared to engaging in projects that are less focused on root causes (e.g., resource transfers such as food aid). For instance, there is a sense in which an organization that seeks to help poor farmers 
in the global periphery has a moral obligation to advocate for policy change to address the root cause of depressed grain prices. A policy to reduce or eliminate agricultural price supports would counter the movement of commodities flooding international markets at artificially low prices. But it is not possible to use public funds, generally speaking, to advocate for improved public policies. To do so requires unrestricted funds.

FBOs can arguably impact public policy when they engage their respective faith communities in advocacy initiatives, especially when the faithful constitute influential constituencies. FBOs also have an ability to mobilize those communities on the basis of faith as compared to self-interest. Faith communities and their respective FBOs can ask people to sacrifice on spiritual grounds, even when it is not in their interest (e.g., farmers in rich countries advocating for decreased agricultural price supports). To not ask them to sacrifice is to ignore a critical part of what motivates many people. ${ }^{30}$

This is a difficult hypothesis to analyze. The ten organizations we studied do not all report expenditures relating to structural change. We did find, however, that six of them reported expenditures for categories that are arguably related to structural change. These categories are "peace and justice," "public information/development education" (which is separate from fund-raising), and "advocacy." We recognize that these categories are not perfect, but they should provide at least a rough indicator of overall expenditures focused on structural change.

Once we combined these expenditures for each organization, we converted them into the percentage of overall program expenditures for structural change. In Tables 4 and 5, we also list the amount of public revenue as a percentage of all revenue. What is most striking about the percentage of expenditures going to structural change is how minimal it is. It ranges from 1 to 17 percent. For four of the six organizations, it ranged between a mere 3 and 5 percent. We acknowledge that raising private resources for advocacy work is arguably more difficult than raising them for providing goods and services to people in need. Yet the paltry amount of funding going to impact structural change is surprising, especially given the focus that many organizations have on addressing root causes.

The data show an inconsistent picture of what quantity of funds were actually devoted to structural change relative to revenue secured from public sources. Comparing three FBOs with an equal number of secular INGOs in our sample (those for which we had data), however, we found that our hypothesis is supported by the evidence. ${ }^{31}$ 


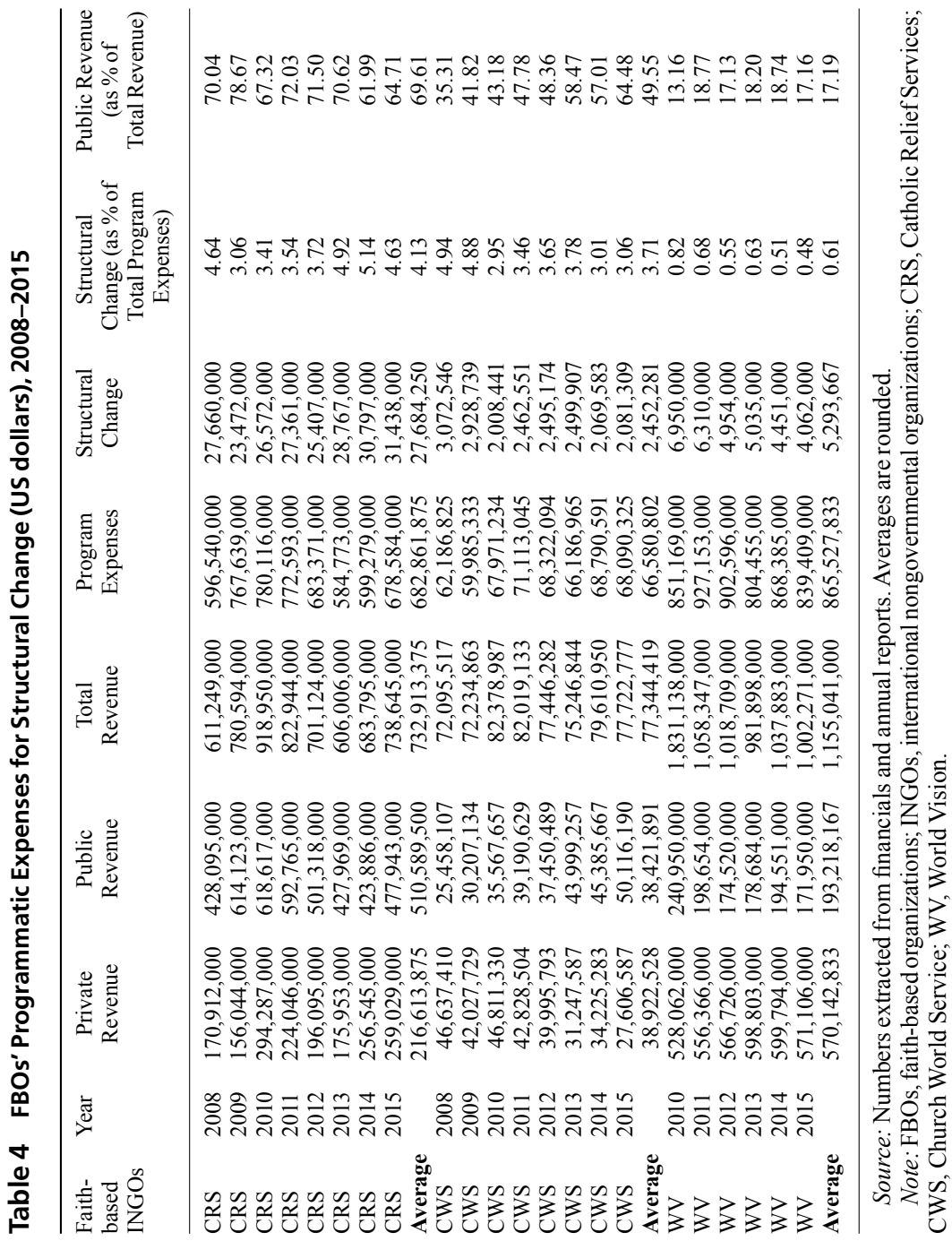




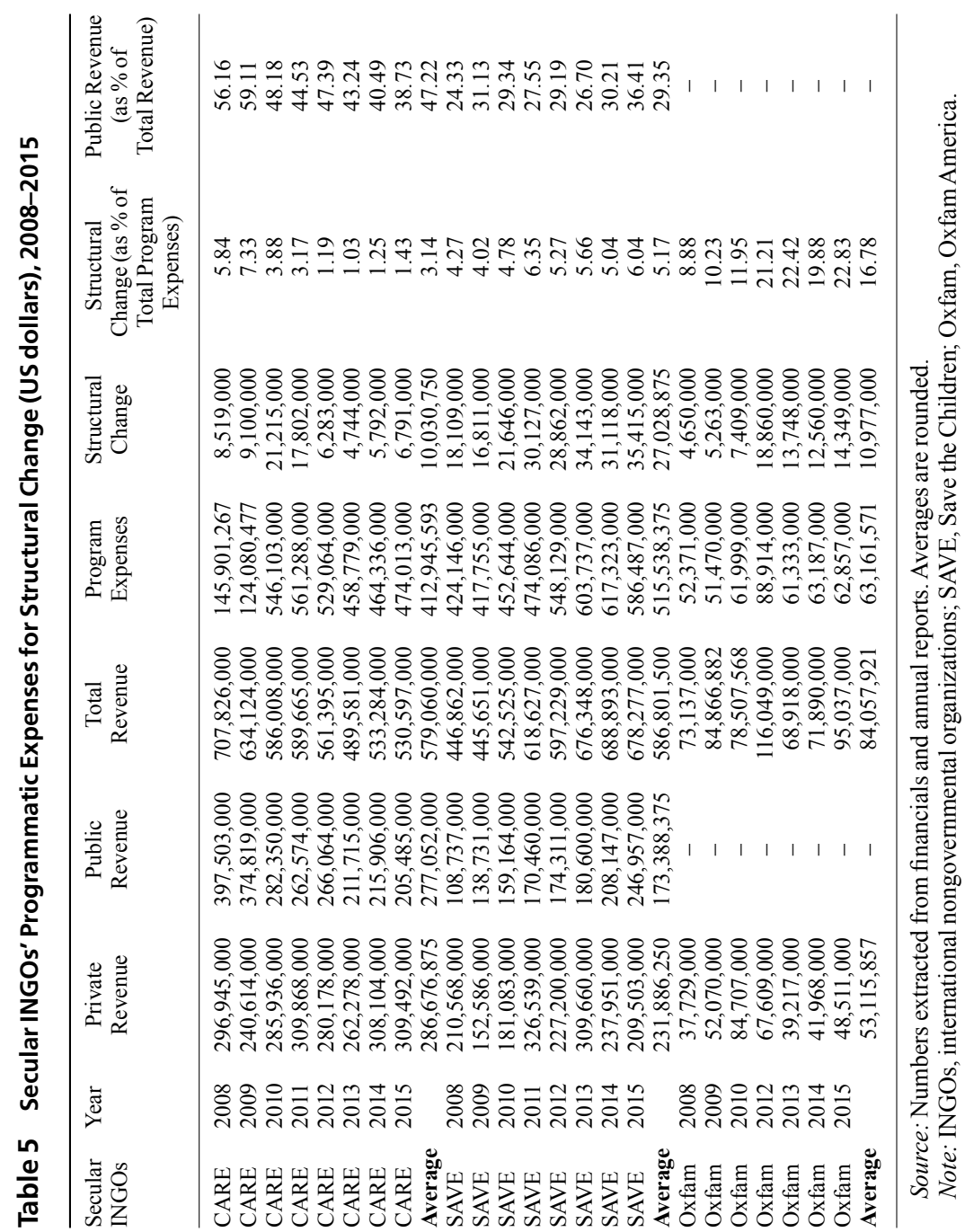




\section{Research Limitations}

We want to be clear about the limitations of our findings. First, in-kind resources can distort calculations of fund-raising efficiency. Donations from drug companies, for instance, can account for sizable private "revenue," which is arguably easier to raise than private unrestricted financial support.

Second, tax documents, annual reports, and websites provide limited information about structural change initiatives. With further research through interviews, we could receive a more complete and nuanced assessment of efforts by FBOs and secular INGOs to change public policy. Our limited sample could be substantially expanded, and outliers could be better understood. ${ }^{32}$

Third, there are segregations of duties among some organizations. For instance, the US Conference of Catholic Bishops engages in public policy advocacy, taking the lead for the official Catholic Church. CRS offers input into the advocacy agenda and provides witnesses for conversations with and testimony to government officials. The heavy lifting for structural change in the United States therefore is done by the Conference of Catholic Bishops, but CRS has considerable influence on that heavy lifting. CRS's actual advocacy impact is therefore arguably much higher than its expenditures on structural change would suggest.

\section{Conclusion}

FBOs and secular INGOs struggle to raise money. There is an understandable tendency among their executive leaders and board members to judge the merits of their organizations on the size of their overall budgets. A large budget seemingly enhances an organization's importance and maybe makes it more prestigious in the minds of its supporters.

While having a large budget provides FBO and secular INGO executives and board members a place at the table with public donors, we contend that the gravitational pull of using greater amounts of public resources must, at times, be resisted. That is because for some organizations, perhaps most especially for FBOs, there exists a natural ease of access, without a gravitational pull, for sitting at different tables. Frankly, being called to a meeting of large FBOs and secular INGOs at USAID headquarters can make top executives and board members feel important. This is sitting at the public money table. In contrast, meeting with a group of church activists about an advocacy initiative - to reduce corruption, for instance - is sitting at a different table altogether. It is an organizational conduit table. To sit at that table typically involves less money. It demands greater humility, in embracing a view that "being big" is not necessarily better.

It is important that FBO and secular INGO leaders guard unrestricted funds so they are able to engage conduits. They should be far less inclined to use their private unrestricted funds as matches for public grants. And public donors should consider demanding reduced or no private matches. 
We want to acknowledge that there is no automaticity in organizational behavior. There are merely tendencies. Organizations can be led by top executives and board members to be selective in what public money they accept. Selectively choosing when to accept public funding requires clarity and discipline. Some organizations no doubt have both.

We suggest that FBOs and secular INGOs develop an organizational mechanism to identify, promote, and seize opportunities afforded by their conduits. Most FBOs and secular INGOs already have something similar-a separate security arm. This arm sometimes restricts enthusiastic program staff members who are eager to initiate projects, with little concern for security. Similarly, a separate arm of FBOs and secular INGOs could routinely make a determination on engagement of conduits, thereby providing guidance to senior management as to where to work, what to work on, with whom to work, and which public grants to pursue or not.

Establishing such an organizational mechanism begs dual questions regarding planning and accountability. When planning within a given country program, the criteria need to be expanded beyond fidelity to mission and the numbers of beneficiaries, costs, and other quantitative indicators. Strategic planning should also involve the five steps to identify optimal conduit engagement enumerated in the section Conduits of FBOs and Secular INGOs: (1) listing humanitarian initiatives by order of importance; (2) identifying the conduits available to engage in pursuing those initiatives; (3) assessing the exclusivity of the conduit; (4) determining the ability to commit the amount of resources needed for the initiative; and (5) deciding if a dogged focus on the initiative can be maintained over the time frame necessary.

The extent to which country programs use these five steps and take action on them can be aggregated at an organizational level in an effectiveness audit. This is more nuanced than merely whether a given organization is operating in line with its mission, and whether it is spending its resources responsibly. That unsophisticated formulation perhaps is fine for profit-maximizing enterprises, but it is insufficient for organizations engaged in the work of socioeconomic, and sometimes spiritual, transformation.

Further research is needed on how FBOs and secular INGOs can most effectively engage their conduits. Such research should explore, for instance, the degree to which social entrepreneurship has an important role in engaging conduits. Persuading Catholic leaders in Haiti to undertake collectively an anticorruption campaign on the basis of morality and right relationships, for instance, requires skill, determination, and endurance. To use John Paul Lederach's terminology, it requires "moral imagination." 33

Imagine stepping into a country with intense humanitarian challenges. You look through your binoculars and see the entire landscape of needs. Above them, you see the initiatives that could satisfy those needs. The initiatives that you and your coworkers are in the best position to address due to your conduits are shaded 
in a different color (based on an assessment using the five steps above). You know your headquarters will back you in pursuing those initiatives, even if you attract less or no public funding in the process. You know your organization's ethos is to stick with those initiatives for as long as it takes. You know your organization is committed to fulfilling its unique role in the humanitarian marketplace.

\section{Notes}

Joseph G. Bock has twelve years of experience in humanitarian relief and development. $\mathrm{He}$ served as country representative in Islamabad and Jerusalem for Catholic Relief Services and as an executive with the American Refugee Committee. He has been a consultant to the World Bank and the Asia Foundation. He is currently director of the School of Conflict Management, Peacebuilding and Development at Kennesaw State University. Ziaul Haque is a PhD student in the School of Conflict Management, Peacebuilding and Development at Kennesaw State University and is an assistant professor in Peace and Conflict Studies at the University of Dhaka, Bangladesh. He has experience in election monitoring in Bangladesh.

1. We do not know the origin of the phrase "humanitarian marketplace." We found it used by Martin Gottwald, Competing in the Humanitarian Marketplace: UNHCR's Organizational Culture and Decision-making Processes (Geneva: UN High Commission for Refugees, 2010), www.unhcr.org/en-us/research/working/4cb41 ef49/competing -humanitarian-marketplace-unhcrs-organizational-culture-decision.html, accessed 17 September 2017.

2. Detlef Pollack, "Varieties of Secularization Theories and Their Indispensable Core," Germanic Review: Literature, Culture, Theory 90, no. 1 (2015): 60-79.

3. Mark Chaves, "Secularization as Declining Religious Authority," Social Forces 72, no. 3 (1994): 749-774; Vesna Malesevic, "Ireland and Neo-secularization Theory," Irish Journal of Sociology 18, no. 1 (2010): 22-42.

4. Interestingly, Cecelia Lynch and Tanya B. Schwarz found little evidence of proselytizing by FBOs. See Cecelia Lynch and Tanya B. Schwarz, "Humanitarianism's Proselytism Problem," International Studies Quarterly 60, no. 4 (2016): 636-646. They found more evidence of "donor proselytism," explained as when donors put pressure on FBOs to "conform to neoliberal conceptions of efficiency, sustainability, and measureable results" (p. 636). Jonathan D. Smith argues that the distinction between FBOs and missionaries is largely artificial. See Jonathan D. Smith, "Positioning Missionaries in Development Studies, Policy, and Practice," World Development 90, iss. C (2017): 63-76.

5. For a helpful distillation of the distinction between a secular INGO and its employees' lack or presence of religiosity, see Emma Tomalin, "Thinking About Faith-based Organizations in Development: Where We Got to and What Next?" Development in Practice 22, nos. 5-6 (2012): 689-703.

6. In this sense, we differ in our view from Tomalin that in secular INGOs "religion is not considered to have a formal or direct influence on the organization" (ibid., p. 701). To the extent that a secular INGO engages with a religious organization due to a relationship of an individual employee or group of employees, then that, to us, constitutes a direct influence. Ibid., pp. 689-703.

7. Ibid., p. 700. 
8. Tomalin provides a helpful summary of this literature. Ibid., pp. 689-703.

9. Alyson Lipsky, "Evaluating the Strength of Faith: Potential Comparative Advantages of Faith-based Organizations Providing Health Services in Sub-Saharan Africa," Public Administration and Development 31, no. 1(2011): 25-36. For another helpful article on comparative advantage related to the challenges in the humanitarian marketplace, see Bruno De Cordier, “The 'Humanitarian Frontline,' Development and Relief, and Religion: What Context, Which Threats and Which Opportunities?" Third World Quarterly 30, no. 4 (2009): 663-684.

10. David Ricardo, “On the Principles of Political Economy and Taxation," in Piero Sraffa, ed., Works and Correspondence of David Ricardo, vol. 1 (Cambridge: Cambridge University Press, 1951), pp. 128-189.

11. Tomalin, "Thinking About Faith-based Organizations in Development," p. 700.

12. Lipsky, "Evaluating the Strength of Faith," pp. 25-36.

13. Of course, goods and services can be produced within the humanitarian marketplace that are then exchanged or traded in the commercial marketplace, as when a microenterprise sells products in a bazaar, or when food aid that is intended for consumption is sold.

14. Note that there is evidence that public funding for explicitly religious programs is acceptable practice in the eyes of some donors, especially in engaging "peaceful religion" that can dissuade "dangerous religion." There is a sense that in the post-Cold War era we are in a "postsecular" period, involving a "religious resurgence." See Elizabeth Shakman Hurd, "International Politics After Secularism," Review of International Studies 38, no. 5 (2012): 943-961.

15. Nina W.T. Hall, “A Catalyst for Cooperation: The Inter-Agency Standing Committee and the Humanitarian Response to Climate Change," Global Governance 22, no. 3 (2016): 369-387.

16. Steven W. Semler, "Systematic Agreement: A Theory of Organizational Alignment," Human Resource Development Quarterly 8, no. 1 (1997): 23-40.

17. Norman H. Chorn, "The 'Alignment' Theory: Creating Strategic Fit," Management Decision 26, no. 1 (1991): 20-24. Note that he identifies four dimensions in need of alignment: "competitive situation, strategy, organizational culture and leadership style," p. 20.

18. See Jaco Cilliers and Robin Gullick, eds., The CRS Justice Lens Case Studies: Reflections on Justice, Solidarity and Peacebuilding in CRS Programming (Baltimore: Catholic Relief Services, 2004), www.mreza-mira.net/wp-content/uploads/The-CRS -Justice-Lens-Case-Studies-Reflections-on-Justice-Solidarity-and-Peacebuilding-in -CRS-Programming.pdf.

19. These were derived from a distillation of church teachings by staff members of the US Catholic Conference, now renamed the US Conference of Catholic Bishops. See "Seven Themes of Catholic Social Teaching," (Washington: USCCB, 2016), www.usccb .org/beliefs-and-teachings/what-we-believe/catholic-social-teaching/seven-themes-of -catholic-social-teaching.cfm, accessed 18 October 2016.

20. Nikolai Hegertun, “Faith-based Mediation? Sant' Egidio's Peace Efforts in Mozambique and Nigeria" (master's thesis, University of Oslo, 2010), www.duo.uio.no/ bitstream/handle/10852/12948/NikolaixHegertunxALLERxsiste.pdf?sequence $=2 \&$ isAllowed=y, accessed 17 September 2017. 
21. HarassMap provides an example of what is involved in cultivating such a social movement. See HarassMap, "Who We Are," http:/harassmap.org/en/what-we-do/, accessed 21 September 2017.

22. These fall into the category of "wicked problems" as defined by C. West Churchman in "Wicked Problems," Management Science 14, no. 4 (1967): B-141-B146.

23. There are, of course, other authors who analyze FBOs outside of the United States. See, for instance, Rick James, "What Is Distinctive About FBOs? How European FBOs Define and Operationalize Their Faith," Praxis Paper No. 22 (Oxford: INTRAC, 2009), pp. 1-22, http://dspace.africaportal.org/jspui/bitstream/123456789/24075/1/What $\% 20$ is \%20distinctive\%20about\%20FBOs.pdf?1, accessed 1 October 2017.

24 . We ran a $t$-test (two-sample, assuming unequal variances) on all observations of these two groups, getting a $p$ value of 0.0244 , which is less than $.1(\alpha=0.1)$, which means that there is a discernable difference between the two groups, but that there is a 10 percent chance that there is no difference. We believe a .1 significance level threshold is appropriate given the relatively small sample size that we have.

25. This finding is inconsistent with the outcome of a different study, though the latter measured differences in both the United States and the United Kingdom. See Malcolm Harper, D.S.K. Rao, and Ashis Kumar Sahu, Development, Divinity and Dharma-The Role of Religion in Development and Microfinance Institutions (Warwickshire: Practical Action, 2008).

26. Nathan Grills, "The Paradox of Multilateral Organizations Engaging with Faithbased Organizations," Global Governance 15, no. 4 (2009): 505-520.

27. Michael Edwards and David Hulme, "Too Close for Comfort? The Impact of Official Aid on Nongovernmental Organizations," World Development 24, no. 6 (1996): 961-973.

28. Shena R. Ashley and David M. Van Slyke, "The Influence of Administrative Cost Ratios on State Government Grant Allocations to Nonprofits," Public Administration Review 72, no. 1 (2012): S47-S56; Arthur C. Brooks, "Is There a Dark Side to Government Support for Nonprofits?" Public Administration Review 60, no. 3 (2000): 211-218; Chao Chao, "When Government Becomes the Principal Philanthropist: The Effects of Public Funding on Patterns of Nonprofit Governance," Public Administration Review 67, no. 3 (2007): 458-473.

29. Margaret F. Sloan and Cleopatra Grizzle, "Assessing the Impact of Federal Funding on Faith-based and Community Organization Program Spending," Public Budgeting and Finance 34, no. 2 (2014): 44-62; John Mandeville, "Public Policy Grant Making: Building Organizational Capacity Among Nonprofit Grantees," Nonprofit and Voluntary Sector Quarterly 36, no. 2 (2007): 282-298.

30 . It is an exaggeration to say that faith communities have failed in giving their members reasons for profound sacrifice and, therefore, that some young people are attracted to extremist groups. Research on recruitment into extremist groups, however, including violent ones like the Islamic State, shows that people — especially young people — hunger for a cause for which to sacrifice, thereby "giving their lives significance." See, for instance, Bruce Bower, "Deadly Devotion: New Studies Explore Why Ordinary People Turn Terrorist," Science News 190, no. 1 (2016): 18.

31 . We ran a $t$-test (two-sample, assuming unequal variances) on all observations 
between the two groups, getting a $p$ value of 0.0009 , which is less than .1 $(\alpha=0.1)$, which means that there is a discernable difference between the two groups.

32. For instance, World Vision, an FBO, receives only around 17 percent of revenue from public sources, which we would expect to result in a relatively robust focus on structural change. We found, however, that it averages only a 1 percent expenditure on structural change.

33. John Paul Lederach, The Moral Imagination: The Art and Soul of Building Peace (Oxford: Oxford University Press, 2005). 